\title{
Flexible surgical training in Australasia
}

\section{Establishing part-time surgical training posts may be difficult, but evidence suggests it is possible and increasingly necessary}

Simon A Williams MB BS, FRACS, FAOrthA Censor-in-Chief

Royal Australasian College of Surgeons, Melbourne, VIC

college.cic@ surgeons.org

doi: 10.5694/mjal3.1034

Research p 423

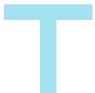

he study by McDonald and colleagues confirms previous reports in Australia and elsewhere that there is a significant difference between the number of trainees who are undertaking some of their surgical training part-time and those who would be interested in doing so. ${ }^{1}$

It cannot be denied that doctors entering a career in surgery are now seeking a more balanced lifestyle. Generational change and associated lifestyle expectations, the feminisation of the workforce and changing working environments have contributed to the trend. ${ }^{2}$

While the Royal Australasian College of Surgeons (RACS) has had a policy supporting flexible surgical training for some years, ${ }^{3}$ it recognises that, by itself, this is not enough. The RACS has recently established the Flexible Training Working Party to look at how we can make the option of part-time training more of a reality for our trainees. Members of the working party include jurisdictional (ie, hospital and health department) representatives, and representatives from Colleges with a higher uptake of part-time training than the RACS. Jurisdictional representation on this working party is extremely important, as the College itself does not employ trainees; while it can accredit trainee posts, it does not create them.

The Royal Adelaide Hospital has successfully implemented an effective model for part-time surgical training. ${ }^{4}$ Interestingly, the position came about after lobbying to the state government produced the funding for a stand-alone 0.5 full-time equivalent position. An early concern for the hospital was the lack of guarantee that the post would be filled from year to year. However, the post has proven popular with trainees, with some even relocating from interstate to take up the position. It is important to note that this post is an accredited position with appropriate learning experiences for the trainee, and not a position designed to satisfy a trainee's wish for a part-time commitment.

Several commentators have raised concerns that parttime training in surgery will affect the educational experience and that a lack of continuity may be an impediment to gaining proficiency in both technical and nontechnical skills. ${ }^{5}$ Contrary to this is logbook evidence from the Royal Adelaide Hospital post, which showed equivalence between 12 months of flexible training and a full-time 6-month position. Furthermore, all trainees who undertook this part-time position subsequently obtained their Fellowship of the RACS. ${ }^{4}$

There is no doubt that some doctors are put off pursuing surgical training because it is not seen as compatible with raising a family or having an appropriate work-life balance. This contributes to the imbalance between the sexes in surgery, with only $30 \%$ of applicants for surgical training in 2012 being women. Although this has improved from the $9 \%$ of current active Fellows who are female, ${ }^{6}$ more than $50 \%$ of new graduating doctors are women, and more needs to be done to ensure surgery is not limiting its pool of available candidates.

The educational concerns relating to part-time training will continue to be debated, but McDonald et al's study demonstrates a desire from trainees for flexible training options. Although the current surgical clinical training environment is not conducive to establishing posts that are less than full-time, the evidence suggests that it is possible. There is a real risk that the limited availability of flexible training options may deter some doctors from entering the field of surgery. However, until there are a proportion of flexible options for training available, these issues and concerns cannot be fully substantiated or explored. It is hoped that the outcomes of the RACS Flexible Training Working Party will lead to the establishment of more flexible training posts, enabling the many questions and issues raised to be resolved.

Competing interests: No relevant disclosures.

Provenance: Commissioned; not externally peer reviewed.

1 McDonald RE, Jeeves AE, Vasey CE, et al. Supply and demand mismatch for flexible (part-time) surgical training in Australasia. Med J Aust 2013; 198 . 423-425.

2 Tomlinson J, Bollard R, Colville DJ, et al. Flexible surgical training: it is time for change. ANZ J Surg 2012; 82: 866-867.

3 Surgical Education and Training Department, Royal Australasian College of Surgeons. Trainee registration and variation policy (ETA-SET-010). Clause 3.4: part time training. Melbourne: RACS, 2011. http://www.surgeons.org/media/ 347659/pol_2011-11-07_trainee_registration_and_variation_policy_v2.pdf (accessed Mar 2013)

4 Neuhaus S, Igras E, Fosh B, Benson S. Part-time general surgical training in South Australia: its success and future implications (or: pinnacles, pitfalls and lessons for the future). ANZ J Surg 2012; 82: 890-894.

5 Truskett P. Is part-time surgical training feasible? ANZ J Surg 2012; 82 859-860.

6 Royal Australasian College of Surgeons. Annual activities report January December 2012. Melbourne: RACS, 2013. http://www.surgeons.org/media/ 18942380/rpt_2013-03-5_jan-dec_ar_final_no_cover.pdf (accessed Mar 2013). • 